\title{
РЕАКЦИИ НЕКОТОРЫХ ЭНДОКРИННЫХ ЖЕЛЕЗ У КРЫСЯТ - САМЦОВ НА ГИПОКСИЮ ВО ВТОРОЙ ФАЗЕ ПОЛОВОГО СОЗРЕВАНИЯ
}

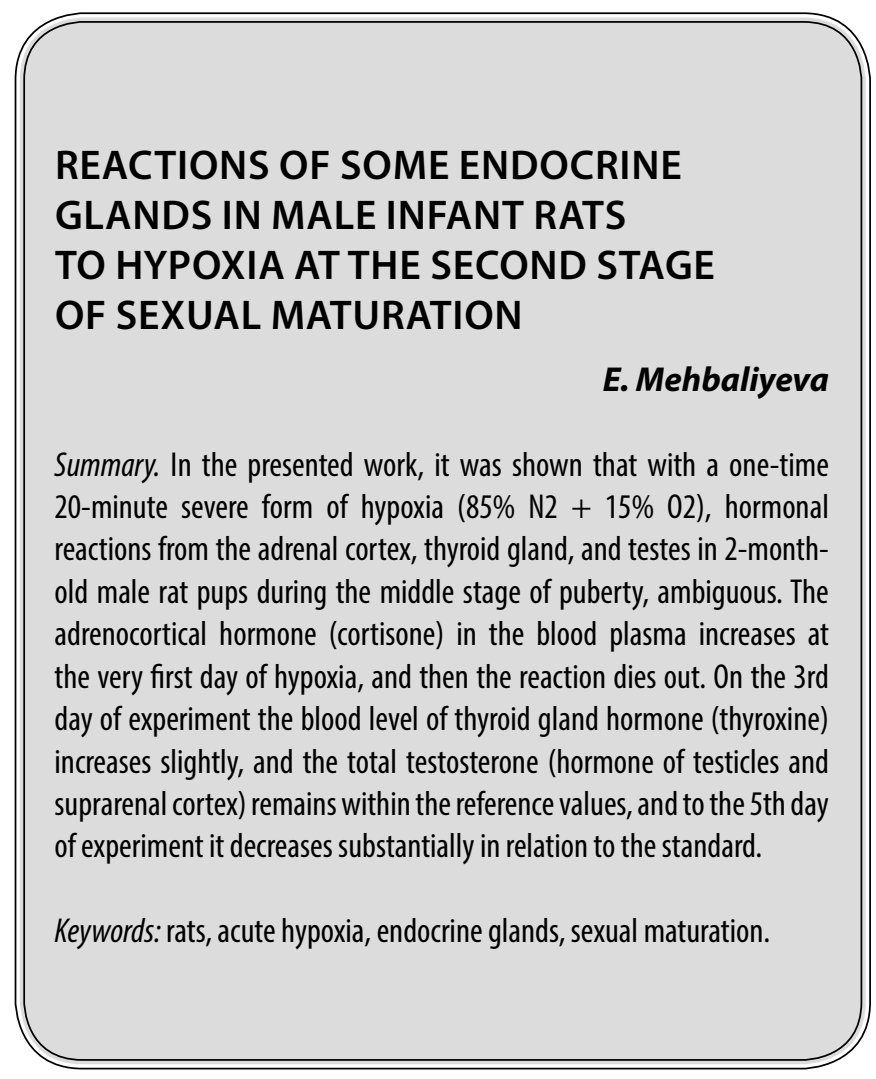

Д ля организма человека и животных, особенно в ранние периоды постнатального онтогенеза, эпизоды острой нехватки кислорода $\left(\mathrm{O}_{2}\right)$ (гипоксия) является жизнеугражающим фактором, приводящий иногда к его гибели.

По данным литературы, воздействие гипоксии вызывает в клетках и тканях организма сложные, обратимые и необратимые изменения как специфического, так и общего характера, а (многие постгипоксические изменения имеют либо адаптивной, либо же патологической направленности [10]. При этом в русле ранних (первичных) реакций происходит нарушение в клеточных митохондриальных биохимических циклах окислительного фосфорилирования, призванные обеспечить организма достаточным количеством свободный энергии [2], а нехватка АТФ (аденизинтрифосфат) отрицательно сказывается на возбудимость и деятельность нейронов головного мозга, мышечных и железистых клеток [5]. При этом нарушается также синтез ряда функционально важных нейропептидов, медиаторов и гормонов [7, 11], сопряженность системных механизмов нервной и нейроэндо-

\author{
Мехбалиева Елнара Джабировна \\ Азербайджанский Государственный Педагогический \\ Университет, Баку, Азербайджан \\ mehbaliyeva79@mail.ru
}

Аннотация. В представленной работе показано, что при одноразовой 20-ти минутной тяжелой формы гипоксии $(85 \% \mathrm{~N} 2+15 \%$ 02) гормональные реакции со стороны коры надпочечников, щитовидной железы и семенников у 2-х месячных крысят - самцов в период средней стадии полового созревания, неоднозначны. Адренокортикальный гормон кортизол в плазме крови повышается в первый же день гипоксии, а дальше реакция затухается. На 3-й день опыта в крови несколько возрастает уровень гормона щитовидной железы тироксина, а содержание тотального тестостерона- гормона семенников и коры надпочечников, остается в пределах контрольных величин и к 5-му дню опыта значительно понижается относительно к норме.

Ключевые слова: крысы, острая гипокция, эндокринных желез полового созревание.

кринной регуляции, осуществление ряда когнитивных и поведенческих реакций [4].

В развитии вторичных (поздних) постгипоксических эффектов важное место занимают реакции вегетативной нервной системы, и особенно ее центрального звена - гипоталамуса. Показано, что гормональная деятельность гипоталамических нейросекреторных клеток и тех эндокринных желез, функциональная активность которых находится под контролем нейротропных гормонов, неоднозначно изменяется при гипоксии [8].

Однако, несмотря на большие успехи в разработке и оценке вопросов проблемы гипоксии, ряд аспекты данного научно-исследовательского направления к настоящему времени остаются малоизученными [3]. В связи с этим, в настоящей работе цель исследования состояла в изучении изменений в секреторной деятельности таких важных периферийных эндокринных желез как кора надпочечников, щитовидная железа и семенников у экспериментально гипоксированных крысят-самцов вступивщих во вторую, среднюю фазу полового созревания. 


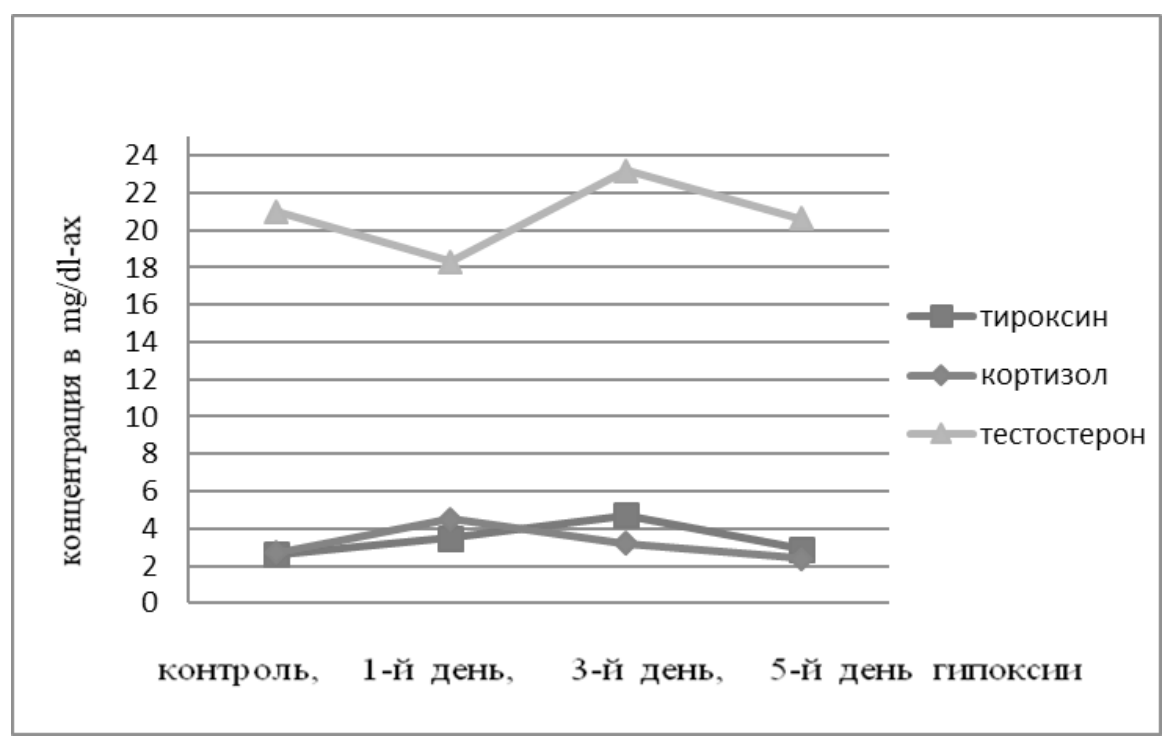

Рис. 1. Кривые изменения концентрации кортизола, тироксина и тестостерона в плазме крови у двухмесячных крысят-самцов до и после острой гипоксии

\section{Методика исследования}

Работа выполнена на 16 двухмесячных белых крысятах - самцах породы Вистар Животные были подразделены на контрольную и опытную группы (в каждой группе п=8). Особи предназначенных для опыта по одному подвергали одноразовой гипоксии в течении 20 мин в малообъемной специальной камере следующим составом газов: азот $\left(\mathrm{N}_{2}\right) 85 \%$ и кислород $\left(\mathrm{O}_{2}\right)$ 15\%. Чтобы нивелировать дополнительного отрицательного действия, выдыхаемого животным $\mathrm{CO}_{2}$, в камеру заранее было вложено определенное количество химпоглатителя $\mathrm{Na}_{2} \mathrm{O}_{2}$.

У каждой контрольной и подопытной особи из бедренной вены систематически брали кровь. С биоэтических позиций работы с экспериментальными животными это малоинвазивный способ, позволяющий в то же время проследить за изменением в крови изучаемого показателя у одного и того же животного в течение всего срока опытов. В плазме крови контрольных и подопытных крысят изучали содержания кортизола (гормона коры надпочечников), тироксина (гормона щитовидной железы) и тотального тестостерона (гормона коры надпочечников и семенников, мужской половой железы). Определение гормонов у подопытных было осуществлено на 1, 3 и 5 день гипоксии.

Определение осуществляли методом иммуноферментного анализа [13]. При этом были использованы наборы реактивов Siemens ADVIA CENTAUR Cp., Lite Reactive. Каждый гормон был изучен в отдельном образце плазмы, применив специального кита. Измерение концентраций гормонов выполнялось на автома- тическом анализаторе. Все анализы были проведены в Центральной Биохимической Лаборатории при Азербайджанском Медицинском Университете по договору о научном содружестве. Полученные данные обработаны статистически с использованием критерия Стьюдента-Фишера. Различия считали достоверными при $\mathrm{p}<0,05$ и ниже.

\section{Результаты исслеАования}

Поскольку в ходе исследования изучали содержания разнообразных гормонов в крови неполовозрелых крысят, то для нас важное значение имела оценка функциональной активности в этом возрасте тех эндокринных желез, которые продуцируют их в организме данного вида животного. Оказалось, что у нормально растущих (интактных) двухмесячных крысят-самцов в крови обнаруживаются разные величины гормонов: содержание адренокортикального гормона кортизола в плазме крови в норме составляло, по нашим данным, 2,7 mg/dl, гормона щитовидной железы тироксина $(2,6 \mathrm{mg} / \mathrm{dl}$, а тотального тестостерона, гормон семенников и коры надпочечников- $21,0 \mathrm{mg} / \mathrm{dl}$ ).

Известно, что кортизол (или гидрокортизон) участвует в регуляции многих внутриклеточных процессов, в углеводном, белковом и жировом (липидном) обмене, стимулирует распада сахаров и белков, активирует образования гликогена в печени путем ускорения дезаминирования глюкогенных аминокислот и превращения их безазотистых остатков в глюкозы, усиливает защитно-адаптивных сил организма, является «стрессорным» гормоном. Тироксин повышает интенсивность внутри 
клеточных окислительных реакций, стимулирует рост и развитие организма, поддерживает возбудимость нервных и мышечных клеток, играет роль в стрессах. А тестостерон активирует функций мужских половых органов и полового поведения, действует на общий обмен веществ, стимулирует синтеза белков, относится к сильным анаболическом гормонам $[1,6,12]$.

Согласно литературным данным, у незрелых животных уровень ряда гормонов в крови, особенно тех, интенсивность выработки и экссекреции которых регулируется через тропных функций (АКТГ, -ТСГ,- и ФСГ -функций) гипоталамо-гипофизарной системы, обычно бывает ниже, чем у зрелых животных. Исследованные нами гормоны, как известно, продуцируются в соответствующих железах под контролем этой системы и наши данные тоже подтверждают выше сказанное. Как уже было отмечено, в крови двухмесячных крысят - самцов, находящихся в средней фазе полового созревания, обнаруживаются сравнительно низкие уровни кортизола и тироксина, и более высокие величины тестостерона.

У этих же крысят гормональные реакции на гипоксию характеризуются некоторыми особенностями. На рис. 1. показаны кривые динамики изменения концентраций кортизола, тироксина и тотального тестетсрона в ранний период воздействия острой гипоксии. Обнаружено, что влияние гипоксии неоднозначно для функциональной активности коры надпочечников, щитовидной железы и семенников, что, по существу, отражается в динамике количественного изменения их гормонов в периферической крови. Более того, величина содержания кортизола первоначально резко возрастает, а затем постепенно снижается к 5-му дню опыта. Тироксин увеличивается лишь на 3-й день гипоксии, а изменения уровня тестостерона по ходу опыта носит иной характер; в начале он резко снижается, потом возрастает, и снова снижается по сравнению с контролем.

В литературе есть сведение о том, что даже пренатальная гипоксия способна изменить уровней кортикостерона и тестостерона в ранний постнатальный период онтогенеза [8]. Нами также показано, у один и трехмесячных экспериментальных животных (крысят и крольчат). что половые гормоны эстрадиол и тестостерон подвержены к уменьшению после гипоксии [9].

Из проведенного эксперимента можно заключить, что в реакции на гипоксию периферийные эндокринные железы подключаются в зависимости от их физиологического роли в организме животного вступающего в цикл полового созревания. В данном случае быстро реагировала на гипоксию адренокортикальная железа, вырабатывающая так называемые «стрессорные гормоны», к числу которых относится также кортизол. По-видимому, щитовидная железа насколько поздно подключается в систему постгипоксических реакций, а половые железы при этом оказываются несколько подавленными в функциональном отношении.

\section{ЛИТЕРАТУРА}

1. Дедов И.М., Меличениченко Г. А., Фадеев В. В. Эндокринология. М., Наука, 2000.

2. Лукьянова Л. Д. Митохондриальная дисфункция — типовой патологический процесс, молекулярный механизм гипоксии /В кн: Проблемы гипоксии: молекулярные, физиологические и медицинские аспекты, М., Истоки, 2001, с. 8-17.

3. Мехбалиева Е. Дж. Проблема гипоксии: фундаментальные аспекты и пути их экспериментального исследования //Известия НАН Азербайджана, сер. биол. и мед., Баку, 2013. с. 109-116. (на азер. языке)

4. Мехбалиева Е. Дж. Первичные и вторичные реакции нервной ткани на нехватку кислорода и их отражение в сложносистемных функциях головного мозга // Вестник Моск. Гос. Обл. Университета, 2014. № 4, с. 32-41.

5. Самойлов М. О. Реакция нейронов мозга на гипоксию. Л., Наука, 1985.

6. Угрюмов М. В. Механизмы эндокринной регуляции, М., Наука, 1999.

7. Chen X. Hypoxiya influens enkefalin realize in rat // Neurorepot, 2000, v.1, n.7, pp. 1555-1558.

8. Herman R.E., Longo L. D., Megivern R. F. Decreased postnatal testosterone and koptikosterone consentration in rats folloving acuteintermitet prenatal hypoxia wit hout alterations in adult mall sex bihovior //Neurotoxicol. and Teratol., 1994, v.16. n.2, pp. 201-206.

9. Mehbalieva E. J. Stady of the action of chronic hypoxia on puberty /Academic Sciense Week- 2015. Inter. Multidiscip Forum. Baku. Azerbaijan, 2015, pp.392-393.

10. Michels C. Physiological and pathological respons to hypoxia //J. Patal., 2004, n.6, pp.1875-1882

11. Mishra O.P., Delhoriya M. Cellular mechanisms of hypoxia inyury in the developing brain // Brain Res. Bull. 1999, v. 48, pp. $233-238$.

12. Whitle R.I., Meikle A. W., Watts N. B. Endokrinology. Part VI: Adrenokortikal stezoids. In: Burtis C. A. Ashwood E. R. ed., Textbook of Clinical Chemistry, 2 nd., ed., 1994, pp. 1808-1821.

13. Wild D. Laboratory Management. The Immonaassy. Handbook, Stocton Press, 1994. 